Case report

\title{
Primary malignant pericardial mesothelioma - a rare cause of pericardial effusion and consecutive constrictive pericarditis:
}

\section{a case report}

Thomas Butz ${ }^{1,2 *}$, Lothar Faber ${ }^{1}$, Christoph Langer ${ }^{1}$, Jan Körfer ${ }^{3}$, Oliver Lindner ${ }^{3}$, Andrea Tannapfel ${ }^{4}$, Klaus-Michael Müller ${ }^{4}$, Axel Meissner ${ }^{2}$, Gunnar Plehn ${ }^{2}$, Hans-Joachim Trappe ${ }^{2}$, Dieter Horstkotte $^{1}$ and Cornelia Piper ${ }^{1}$

\footnotetext{
Addresses: ${ }^{1}$ Department of Cardiology, Heart and Diabetes Center North Rhine-Westphalia, Ruhr-University Bochum, D-32545 Bad Oeynhausen, Germany

${ }^{2}$ Department of Cardiology and Angiology (Medizinische Klinik II), Marienhospital Herne, Ruhr-University Bochum, D-44627 Herne, Germany

${ }^{3}$ Institute of Radiology, Nuclear Medicine and Molecular Imaging, Heart and Diabetes Center North Rhine-Westphalia, Ruhr University Bochum, Bad Oeynhausen, Germany

${ }^{4}$ Institute of Pathology, Ruhr-University Bochum, Berufsgenossenschaftliche Universitätsklinik Bergmannsheil (Deutsches Mesotheliomregister) D-44789 Bochum, Germany

Email: TB* - thomas.butz@marienhospital-herne.de; LF - lfaber@hdz-nrw.de; CL - clanger@hdz-nrw.de; JK - jkoerfer@hdz-nrw.de; OL - olindner@hdz-nrw.de; AT - atannapfel@rub.de; KMM - kmmueller@rub.de; AM - ameissner@rub.de; GP - gplehn@rub.de; HJT - hjtrappe@rub.de; DH - akohlstaedt@hdz-nrw.de; CP - cpiper@hdz-nrw.de

* Corresponding author
}

Received: 20 December 2008 Accepted: 13 March 2009 Published: 17 September 2009

Journal of Medical Case Reports 2009, 3:9256 doi: 10.4076/I752-1947-3-9256

This article is available from: http://jmedicalcasereports.com/jmedicalcasereports/article/view/9256

(c) 2009 Butz et al.; licensee Cases Network Ltd.

This is an Open Access article distributed under the terms of the Creative Commons Attribution License (http://creativecommons.org/licenses/by/3.0), which permits unrestricted use, distribution, and reproduction in any medium, provided the original work is properly cited.

\section{Abstract}

Introduction: Primary malignant pericardial mesothelioma is a very rare pericardial tumor of unknown etiology.

Case presentation: A 6I-year-old Caucasian woman was admitted to our hospital complaining of exertional dyspnea due to a large pericardial effusion. Intrapericardial fluid volume declined after repeated pericardiocentesis, but the patient progressively developed a hemodynamically relevant pericardial constriction. Pericardiectomy revealed a pericardial mesothelioma. Subsequently, four cycles of chemotherapy (dosage according to recently published trials) were administered. The patient remained asymptomatic, and there was no recurrence of the tumor after three years.

Conclusion: Pericardial mesothelioma should be considered and managed appropriately in nonresponders to pericardiocentesis, and in patients who develop constrictive pericarditis late in their clinical course. 


\section{Introduction}

Primary malignant pericardial mesothelioma is a very rare pericardial tumor of unknown etiology.

\section{Case presentation}

A 61-year-old Caucasian woman was admitted to our hospital complaining of exertional dyspnea (NYHA III) and chest pain. Transthoracic echocardiography demonstrated a large pericardial effusion. Pericardiocentesis revealed $1500 \mathrm{ml}$ of an acellular, sterile pericardial effusion and symptoms were markedly relieved.

The patient was re-admitted three months later, and transthoracic echocardiography showed a recurrent large pericardial effusion with partly organized fibrinous structures inside the effusion. There were no signs of cardiac tamponade, but there was a thickened right ventricular pericardium (Figure 1, Movies 1 and 2). Magnetic resonance imaging (MRI) confirmed the pericardial effusion, and the slightly thickened pericardium (Figure 2, Movies 3 and 4).

An F-18 fluorodeoxyglucose positron emission tomography/computed tomography (FDG-PET/CT) scan demonstrated an intrapericardial accumulation of the tracer, indicating a local infection or a tumor (Figure 3) [1].

The patient's level of intrapericardial fluid declined after repeated pericardiocentesis, and cytology of the pericardial fluid revealed signs of chronic infection, but no malignant mesothelial cells. Subsequently, the patient developed a hemodynamically relevant pericardial constriction (Movie 5). Therefore, a partial pericardiectomy was performed, and histological examination (Figures $4 \mathrm{a}$ and $4 \mathrm{~b}$ )

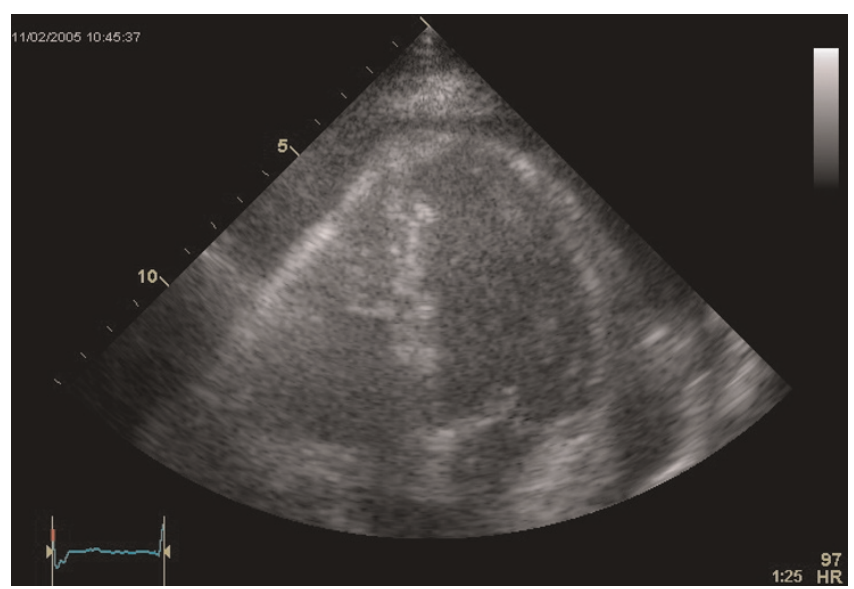

Figure I. Transthoracic echocardiography (apical 4-chamber view) demonstrating a large pericardial effusion and a thickened pericardium of the free wall of the right ventricle (see Movies I and 2).

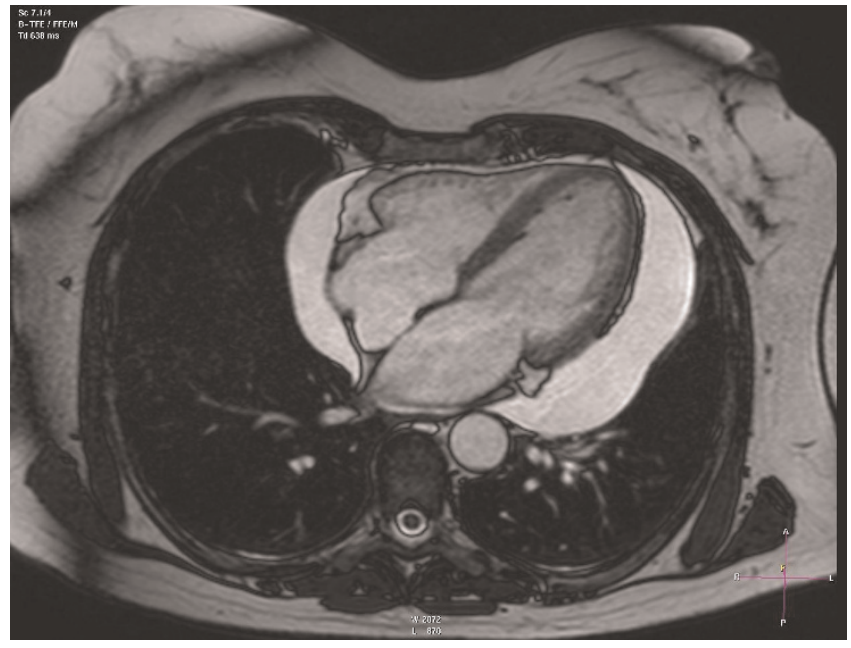

Figure 2. Magnetic resonance imaging (4-chamber view, turbo field echo [TFE]) confirmed the extended pericardial effusion without signs of cardiac tamponade, and a slightly thickened pericardium (see Movies 3 and 4).

revealed a primary malignant pericardial mesothelioma (PMPM). This finding initiated additional subtotal pericardiectomy with resection of as much pericardium as possible. The inspection of the epicardium by the surgeon showed a pericardial thickness of $10 \mathrm{~mm}$ and a whitecolored spot of the pericardium at the right ventricle. There was no indication of tumor spread to adjacent structures, and there was no tumor on the epicardial site.

This was considered to be a PMPM because no signs of a pleural mesothelioma were found. Despite the abovementioned findings of the magnetic resonance imaging (MRI) scan of the chest, FDG-PET, echocardiography and pericardiocentesis, we suspected PMPM but could not definitively declare a preoperative diagnosis of PMPM.

Subsequently, four cycles of chemotherapy with pemetrexed and cisplatin (four cycles in four months - dosage according to recently published trials) were administered, and remission was achieved [2-5]. The patient remained asymptomatic, and there was no recurrence of the tumor during the next three years.

\section{Discussion}

Diagnosis of pericardial diseases can be challenging and often requires a multimodal imaging approach including echocardiography, MRI, CT and FDG-PET scans $[6,7]$. The majority of reported pericardial tumors are metastatic in nature and indicate a poor prognosis. Primary tumors of the pericardium are extremely rare, and PMPM is a very rare pericardial tumor of unknown etiology [8-10]. So far, about 350 cases have been reported in the literature, and 

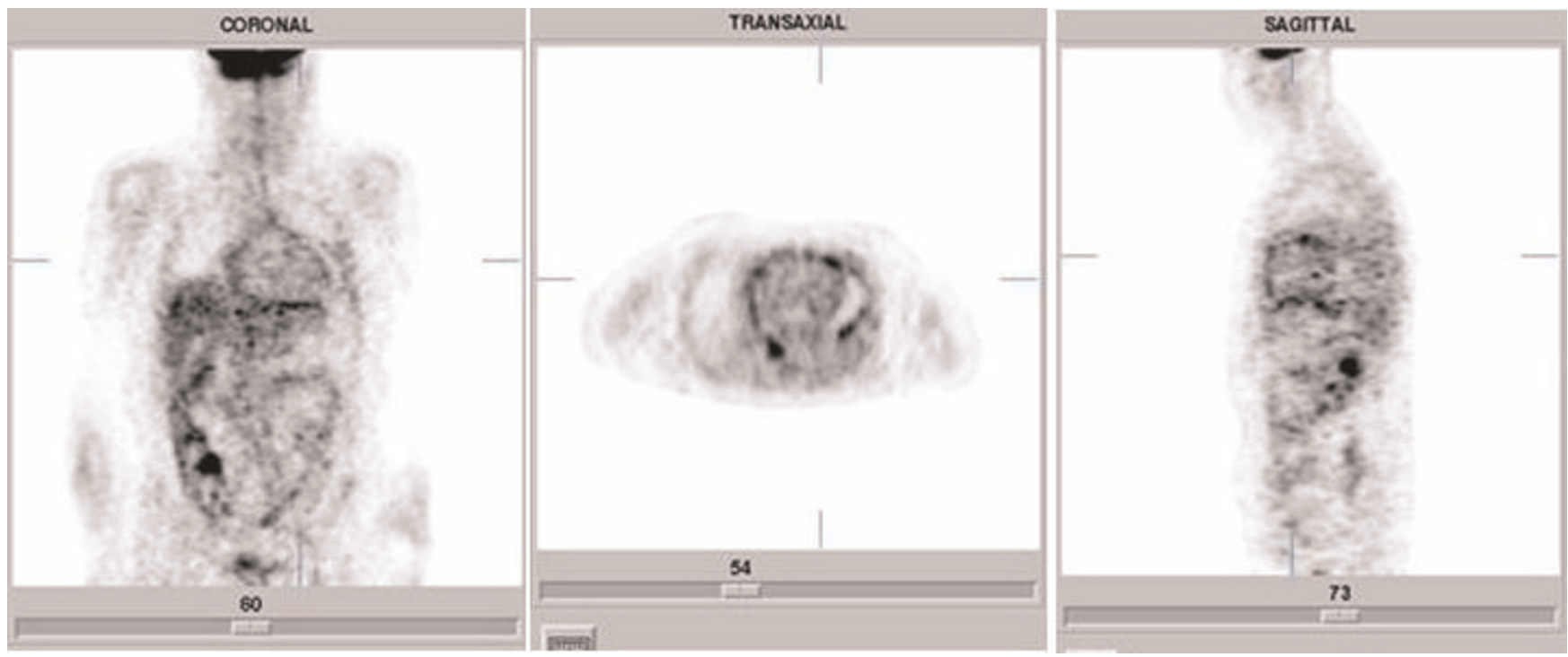

Figure 3. F-I 8 fluorodeoxyglucose positron emission tomography/computed tomography (FDG-PET/CT) scan demonstrating an intrapericardial accumulation of the tracer (Siemens ECAT HR+).

in an epidemiological survey, the annual incidence of PMPM was reported to be one in 40 million (incidence $0.0022 \%)$. PMPM is characterized by atypical solid growth of the mesothelium with formation of atypical cavities surrounded by fibrous stroma.

There is some recent evidence that asbestos may have a harmful effect on pericardial serosa. However, there has not yet been any definite proven association between asbestos exposure and pericardial disease [2,8-10]. Interestingly, our patient had a history of asbestos exposure at work (she worked in a school building).

PMPM is often discovered late during a patient's clinical course or at autopsy. Frequent clinical diagnoses refer mainly to acute pericarditis, constrictive pericarditis, and cardiac tamponade and sometimes to various types of coronary heart disease.

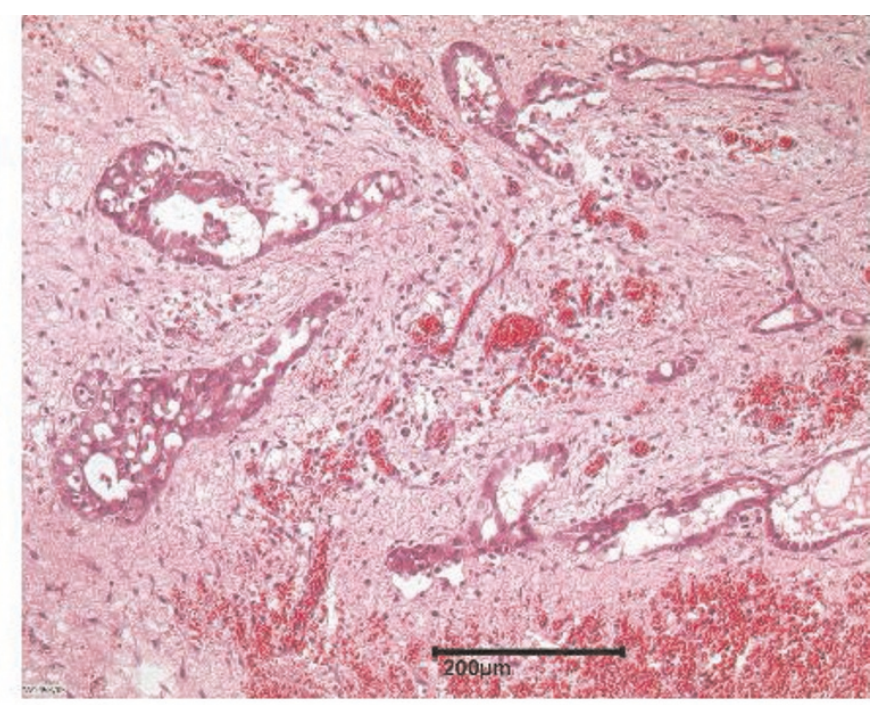

Figure 4ts
Figare ta

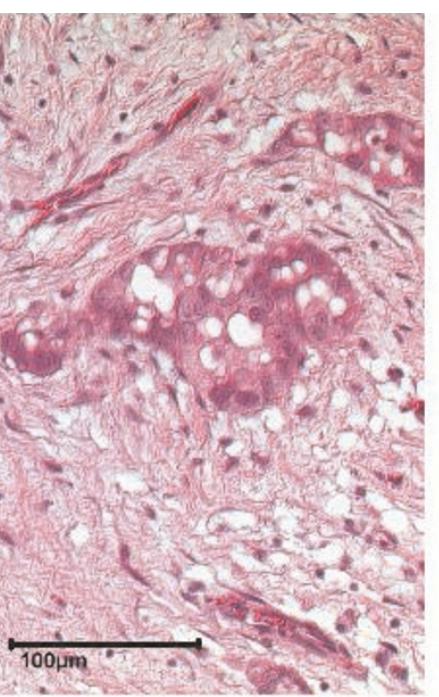

Figure 4. Histological examination revealed diffuse infiltration of the pericardium by epithelioid cells due to the primary malignant pericardial mesothelioma (a: $100 \mu \mathrm{m}$, b: $200 \mu \mathrm{m})$. 
Surgical resection remains the main treatment modality in PMPM. The prognosis of this disease remains extremely poor due to its late presentation, inability of complete tumor eradication by surgery and the poor response of PMPM to radiotherapy or chemotherapy. A median survival time from the onset of symptoms is six months [8-10]. Recently, newer chemotherapeutic regimens after complete excision of the tumor have shown prolonged survival times [2-5].

\section{Conclusion}

PMPM should be considered and managed appropriately in non-responders to pericardiocentesis or pericardial window for treatment of pericardial effusion or tamponade, and in patients who develop constrictive pericarditis late in their clinical course.

\section{Abbreviations}

CT, computer tomography; FDG, 2-fluoro-2-deoxy-Dglucose; FDG-PET, F-18 fluorodeoxyglucose positron emission tomography; MRI, magnetic resonance imaging; PMPM, primary malignant pericardial mesothelioma.

\section{Consent}

Written informed consent was obtained from the patient for publication of this case report and any accompanying images. A copy of the written consent is available for review by the Editor-in-Chief of this journal.

\section{Competing interests}

The authors declare that they have no competing interests.

\section{Authors' contributions}

TB, LF, CL, AM, GP, HJT, DH and CP analyzed and interpreted the patient data regarding the cardiologic disease, therapy and the echocardiographic diagnostic. TB was a major contributor in writing the manuscript. JK analyzed and interpreted the magnetic resonance imaging; OL analyzed and interpreted the FDG-PET. AT and KMM performed the histological examination of the tumor. All authors read and approved the final manuscript.

\section{References}

I. Ost P, Rottey S, Smeets P, Boterberg T, Stragier B, Goethals I: F-18 fluorodeoxyglucose PET/CT scanning in the diagnostic workup of a primary pericardial mesothelioma: a case report. $J$ Thorac Imaging 2008, 23:35-38.

2. Santos C, Montesinos J, Castañer E, Sole JM, Baga R: Primary pericardial mesothelioma. Lung Cancer 2008, 60:291-293.

3. Maruyama R, Sakai M, Nakamura $T$, Suemitsu R, Okamoto $T$, Wataya H, Nishiyama K, Kamei T, Ichinose Y: Triplet chemotherapy for malignant pericardial mesothelioma: a case report. Jpn J Clin Oncol 2000, 36:245-248.

4. Jänne PA, Wozniak AJ, Belani CP, Keohan ML, Ross HJ, Polikoff JA, Mintzer DM, Taylor L, Ashland J, Ye Z, Monberg MJ, Obasaju CK: Open-label study of pemetrexed alone or in combination with cisplatin for the treatment of patients with peritoneal mesothelioma: outcomes of an expanded access program. Clin Lung Cancer 2005, 7:40-46.
5. Taylor P, Castagneto B, Dark G, Marangolo M, Scagliotti GV, van Klaveren RJ, Labianca $R$, Serke M, Schuette $W$, van Meerbeeck JP, Heigener D, Liu Y, Adachi S, Blatter J, von Pawel J: Single-agent pemetrexed for chemonaïve and pretreated patients with malignant pleural mesothelioma: results of an International Expanded Access Program. J Thorac Oncol 2008, 3:764-77I.

6. Maisch B, Seferovic PM, Ristic AD, Erbel R, Rienmüller R, Adler Y, Tomkowski, WZ, Thiene G, Yacoub MH: Guidelines on the diagnosis and management of pericardial diseases executive summary; The Task force on the diagnosis and management of pericardial diseases of the European society of cardiology. Eur Heart J 2004, 25:587-6I0.

7. Langer C, Butz T, Horstkotte D: Multimodality in imaging calcific constrictive pericarditis. Heart 2006, 92: 1289.

8. Luk A, Ahn E, Vaideeswar P, Butany JW: Pericardial tumors. Semin Diagn Pathol 2008, 25:47-53.

9. Oreopoulos G, Mickleborough L, Daniel L, De Sa M, Merchant N, Butany J: Primary pericardial mesothelioma presenting as constrictive pericarditis. Can J Cardiol 1999, I5:| 367-I372.

10. Suman S, Schofield P, Large S: Primary pericardial mesothelioma presenting as pericardial constriction: a case report. Heart 2004, 90:e4.

\section{Supplementary Files}

Movie 1. Transthoracic echocardiography demonstrated the recurrence of a large pericardial effusion and a thickened pericardium in the area of the right ventricle. Click on this link to play the movie (MP4): http:// jmedicalcasereports.com/jmedicalcasereports/article/ downloadSuppFile/9256/20505

Movie 2. Transthoracic echocardiography (subcostal view) demonstrating a pericardial effusion and a markedly thickened pericardium. Click on this link to play the movie (MP4): http://jmedicalcasereports.com/jmedicalcasereports/article/downloadSuppFile/9256/20506

Movie 3. Magnetic resonance imaging (MRI) confirmed the extended pericardial effusion without signs of cardiac tamponade, and a slightly thickened pericardium. Click on this link to play the movie (MP4): http://jmedicalcasereports.com/jmedicalcasereports/article/downloadSuppFile/9256/20507

Movie 4. Magnetic resonance imaging (MRI) confirmed the extended pericardial effusion without signs of cardiac tamponade, and a slightly thickened pericardium. Click on this link to play the movie (MP4): http://jmedicalcasereports.com/jmedicalcasereports/article/downloadSuppFile/9256/20508

Movie 5. Transthoracic echocardiography (subcostal view) demonstrating a markedly thickened pericardium and partly organised, fibrinous structures in the effusion. Click on this link to play the movie (MP4): http://jmedicalcasereports.com/jmedicalcasereports/article/downloadSuppFile/9256/20511 